\title{
Apomorphine-Susceptible and Apomorphine-Unsusceptible Wistar Rats Differ in Their Susceptibility to Inflammatory and Infectious Diseases: A Study on Rats with Group-Specific Differences in Structure and Reactivity of Hypothalamic-Pituitary-Adrenal Axis
}

\author{
Annemieke Kavelaars,, ${ }^{1}$ Cobi J. Heijnen, ${ }^{1}$ Bart Ellenbroek, ${ }^{2}$ Henk van Loveren, ${ }^{3}$ and Alexander Cools ${ }^{2}$ \\ 1Department of Immunology, University Hospital for Children and Youth "Het Wilhelmina Kinderziekenhuis," 3501 CA \\ Utrecht, The Netherlands, ${ }^{2}$ Department of Psychoneuropharmacology, University of Nijmegen, 6500 HB Nijmegen, \\ The Netherlands, and ${ }^{3}$ Department of Immunobiology and Haematology, Laboratory for Pathology and Immunobiology, \\ RIVM, 3720 BA Bilthoven, The Netherlands
}

Variability in susceptibility to diseases is a well known phenomenon that has been attributed to genetic and environmental factors. At the level of the immune system, the reactivity of two types of T helper cells (Th1 and Th2 cells) plays an important role in determining disease susceptibility. Inflammatory (autoimmune) diseases are stimulated by cytokines produced by Th1 cells. Th2 cytokines stimulate antibody production (e.g., $\lg \mathrm{E}$ ) and eosinophilia as observed in allergic reactions or during parasitic infections. We describe here that the reactivity in a Th1 or a Th2 disease model significantly differs between individual rats that show group-specific differences in reactivity of the hypothalamic-pituitary-adrenal (HPA) axis, as well as in their behavioral responses to stress.

We used two outbred lines of Wistar rats, apomorphinesusceptible rats that have a relatively hyperreactive HPA axis (APO-SUS) and apomorphine-unsusceptible rats that have a relatively hyporeactive HPA axis (APO-UNSUS). APO-SUS, but not APO-UNSUS, rats generated a vigorous, Th2-dependent IgE response after infection with the nematode Trichinella spiralis. In contrast, APO-UNSUS, but not APO-SUS, rats were susceptible for Th1-mediated experimental autoimmune encephalomyelitis. Investigation of cytokine responses of splenocytes revealed that the ratio of mRNA expression for Th1derived interferon (IFN)- $\gamma$ and mRNA expression of Th2-derived interleukin-4 (IL-4) was significantly smaller in APO-SUS than in APO-UNSUS rats.

In conclusion, individual differences in structure and reactivity of the neuroendocrine system co-occur with group-specific differences in susceptibility to inflammatory and infectious diseases.

Key words: experimental autoimmune encephalomyelitis; $T$ cells; hypothalamus-pituitary-adrenal axis; rats; Trichinella spiralis; interferon- $\gamma$; interleukin-4
Individual differences in susceptibility to inflammatory and infectious diseases are thought to be determined by the interplay between genetic and environmental factors. The immune system plays a major role in the pathogenesis of inflammatory and infectious diseases. The neuroendocrine system and the immune system interact (Heijnen et al., 1990; Munck and Guyre, 1990; Madden et al., 1995). Thus, it is conceivable that the reactivity of the neuroendocrine system contributes to disease susceptibility.

We focused on two types of rats that are present in each unselected, outbred population of Wistar rats, namely "high responders to novelty" and "low responders to novelty" (Piazza et al., 1989, 1990a,b; Cools et al., 1990, 1993). Since 1985, Cools et al. have been able to breed these two types of individuals. They have shown that the bimodal variation in apomorphine susceptibility, the original selection criterion for the breeding, is consistently coupled to a bimodal variation in a great variety of neuroanatomi-

Received Nov. 12, 1996; revised Jan. 9, 1997; accepted Jan. 13, 1997.

We are greatly indebted to Dr. H.-D. Volk, Institut fur Medizinische Immunologie, Humboldt University, Berlin, Germany, for providing the plasmid for the competitive PCR. We thank Conny Verbaas, Jitske Zijlstra, Anita Meijer, and Gerard Geelen for skillful technical assistance.

Correspondence should be addressed to Dr. Annemieke Kavelaars, Department of Immunology, University Hospital for Children and Youth "Het Wilhelmina Kinderziekenhuis," P.O. Box 18009, 3501 CA Utrecht, The Netherlands.

Copyright (C) 1997 Society for Neuroscience $0270-6474 / 97 / 172580-05 \$ 05.00 / 0$ cal, neurochemical, endocrinological, and behavioral features. Rats marked by a high apomorphine susceptibility (APO-SUS) are high responders to novelty in terms of behavioral response (high exploratory activity) and endocrinological responses (high and long-lasting plasma release of ACTH and corticosteroids). Rats marked by low apomorphine susceptibility (APO-UNSUS) are low responders to novelty in terms of behavioral response (low exploratory activity) and endocrinological responses (low and short-lasting release of ACTH and corticosteroids; Cools et al., 1990; Rots et al., 1995, 1996a,b).

At the level of the immune system, it is thought that two types of $\mathrm{T}$ helper cells play an important role in determining susceptibility to disease. Th1 cells predominantly produce $\gamma$-interferon (IFN- $\gamma$ ) and interleukin-2 (IL-2), which promote cellular immunity (Mosmann and Sad, 1996). In experimental models of autoimmune diseases such as experimental autoimmune encephalomyelitis (EAE), the Th1 type effector cell response is dominant (Mosmann and Sad, 1996). Th2 cells secrete IL-4, IL-5, and IL-10, which provides help for B cell differentiation and humoral immune responses (Mosmann and Sad, 1996). The immune response to infection with parasitic helminths such as $T$. spiralis involve elevated IgE antibody production, eosinophilia, and mastocytosis (Finkelman et al., 1991). These responses are all stimulated by Th2-derived cytokines (Finkelman et al., 1991; Mosmann 
and Sad, 1996). Alterations of the cytokine pattern in vivo can reverse host resistance or susceptibility to disease (Liblau et al., 1995). The production of Th1 and Th2 cytokines can, at least in vitro, be modulated by neuroendocrine mediators (Daynes and Araneo, 1989; Daynes et al., 1990; Rook et al., 1994). It is not known, however, whether the neuroendocrine system in vivo contributes to the Th1/Th2 balance and to disease susceptibility. However, studies in inbred rats have presented evidence that the neuroendocrine system can contribute to susceptibility to inflammatory autoimmune disease (Macphee et al., 1989; Sternberg et al., 1989a,b). Rats with a blunted reactivity of the HPA axis like Lewis rats are susceptible to EAE and arthritis, whereas Fischer F344 rats are resistant in models of autoimmunity (Macphee et al., 1989; Sternberg et al., 1989a). Moreover, we have evidence that APO-SUS and APO-UNSUS animals differ in EAE susceptibility (Cools et al., 1993).

The aim of the present study was to establish whether the reactivity of the neuroendocrine system of APO-SUS and APOUNSUS rats is coupled to a group-specific reactivity in two fundamentally different disease models, namely the EAE model for Th1-dependent, autoimmune diseases and the IgE response to infection with the nematode $T$. spiralis for Th2-dependent, infectious diseases.

\section{MATERIALS AND METHODS}

Animals. Male Wistar rats of the APO-SUS and APO-UNSUS lines bred and reared in the Central Animal Laboratory of the University of Nijmegen were used. The selection procedure has been described in detail by Cools et al. (1990). In short, a group of 60 male and 60 female rats of an outbred Wistar population was given s.c. injections of $1.5 \mathrm{mg} / \mathrm{kg}$ apomorphine, which induces a stereoptypic gnawing behavior. The gnawing score was determined in a modified "Ungerstedt-box," allowing a quantitative analysis of the computerized and automated recordings of gnawing per 45 min (Cools et al., 1990). Breeding of the APO-UNSUS line was started with nine pairs of rats with a gnawing score of $<10$ per $45 \mathrm{~min}(27 \%$ of the original population). Breeding of the APO-SUS rats was started with nine pairs of rats with a gnawing score of $>500$ per $45 \min (23 \%$ of the original population). Throughout the breeding procedure, retention of the genetic feature was tested continuously in rats of the first litter of each generation. After weaning at the age of $30 \mathrm{~d}$, males and females were separated and grouped together (2-4 rats per cage per sex per selection line). At the age of $60 \mathrm{~d}$, rats were given injections of the dopaminergic agonist apomorphine $(1.5 \mathrm{mg} / \mathrm{kg}$, s.c. $)$ and the gnawing was tested. Male rats of the second and third litter of APO-SUS rats (gnawing scores in first litter $>500$ per $45 \mathrm{~min}$ ) and of APO-UNSUS rats (gnawing scores in first litter $<10$ per $45 \mathrm{~min}$ ) were used for the experiments. The experimental animals belonged to the 13th to 18th generations, were housed and grouped together $(2-6)$ in macrolon cages $(40 \times 25 \mathrm{~cm})$, and were maintained on a $12 \mathrm{hr}$ light/dark cycle. Standard lab chow and water were available ad libitum. Animals tested for EAE and T. spiralis belonged to the same generation, and experiments were performed in parallel. All experiments were performed in accordance with international and institutional guidelines for animal care.

EAE. Seven APO-SUS and seven APO-UNSUS rats of 250-350 gm were inoculated subcutaneously in the hind paw with $100 \mu$ l of inoculate under brief halothane anesthesia. The inoculate consisted of $1500 \mu \mathrm{g}$ of myelin basic protein (MBP) in $1 \mathrm{ml}$ saline mixed with $1 \mathrm{ml}$ complete Freund's adjuvant (CFA) (Difco, Detroit, MI), to which $10 \mathrm{mg}$ Mycobacterium tuberculosis H37Ra was added. Rats were examined daily to score the development of clinical signs of EAE. Clinical signs were scored on a scale from $0-5$ : 0 , no clinical signs; 1 , partial paralysis of the tail; 2 , paralyzed tail; 3, paresis of the hindlimbs; 4, complete paralysis of the hindlimbs or complete lower part of the body; 5, death as a result of EAE.

Trichinella spiralis infection. T. spiralis L1 larvae were prepared from source rats as described (Schlumpf et al., 1994). Nine APO-SUS and seven APO-UNSUS rats were infected per os with 1000 L1 larvae. Six weeks after infection, rats were sacrificed and serum was collected. Serum levels of $\operatorname{IgG}, \operatorname{IgA}$, and $\operatorname{IgE}$ antibodies specific for $T$. spiralis were determined as described previously (Schlumpf et al., 1994).

In vitro cytokine production. To test the capacity of splenocytes to produce the Th1 cytokine IFN- $\gamma$ after mitogenic stimulation, splenocytes $\left(10^{6} / \mathrm{ml}\right)$ of APO-SUS and APO-UNSUS rats were cultured in RPMI1640 (Life Technologies, Grand Island, NY) supplemented with antibiotics and 5\% heat-inactivated FCS (Gibco) with the polyclonal activator PMA $(10 \mathrm{ng} / \mathrm{ml})$ plus ionomycine $(400 \mathrm{ng} / \mathrm{ml})$ for $20 \mathrm{hr}$. Supernatants were harvested, and the concentration of IFN- $\gamma$ was determined by ELISA (Van der Meide et al., 1990).

Because quantitative tests for measurement of serum level of IL-4 are not yet available, the expression of IL-4 mRNA as well as of IFN- $\gamma$ mRNA was determined by quantitative RT-PCR to gain insight into the relative contribution of Th1 or Th2 type responses in APO-SUS and APO-UNSUS rats. At the time point when the above-mentioned supernatants were collected, cells were harvested and RNA was extracted by the use of RNAzol B (Campro Scientific, Veenendaal, The Netherlands). Two micrograms of RNA were reverse transcribed into cDNA using AMV reverse transcriptase and oligo-dT 12-18 oligonucleotide as primer according to the manufacturer's protocol. Quantitative competition PCR was performed as described by Siegling et al. (1994), who kindly provided us with a competitor plasmid containing primers for $\beta$-actin, IFN- $\gamma$, and IL-4. Serial dilutions of competitor fragment were coamplified with fixed amounts of cDNA. The PCR product for the sample cDNA and the competitor differ in size so that the relative intensities of the two products can be compared. For calculations, 1 unit of cDNA signal was defined as the amount that resulted in equal density of competitor and target cDNA at $1 \mu \mathrm{l}$ of 1:50 dilution of the competitor. The following primer pairs were used: $\beta$-actin sense, $5^{\prime}$-CTATCGGCAATGAGCGGTTC; antisense, $5^{\prime}$ CTTAGGAGTTGGGGGTGGCT; IFN- $\gamma$ sense, 5'-CCTCTCTGGCTGTTACTGC; antisense, 5'-CTCCTTTTCCGCTTCCTTAG; IL-4 sense, 5'-ATGCACCGAGATGTTTGTACC, antisense, 5'-TTTCAGTGTTCT GAGCGTGGA. These primer pairs gave rise to PCR products for $\beta$-actin of $762 \mathrm{bp}$ for sample cDNA and $601 \mathrm{bp}$ for competitor fragment. IFN- $\gamma$ sample cDNA yields a fragment of $419 \mathrm{bp}$, whereas the competitor results in a fragment of 319 bp. For IL-4, sample cDNA results in $275 \mathrm{bp}$ and competitor cDNA in 178 bp. cDNA was amplified in a $20 \mu \mathrm{l}$ reaction volume containing $2 \mu \mathrm{l}$ of $10 \times$ PCR buffer, $0.25 \mathrm{~mm}$ each dNTP, $50 \mathrm{ng} / \mathrm{ml}$ of the appropriate primer pair, $2 \mathrm{mM} \mathrm{MgCl}_{2}$, and serial dilutions of competitor fragment. After 5 min denaturation at $94^{\circ} \mathrm{C}$, cDNA samples were subjected to cycles of denaturation $\left(15 \mathrm{sec}\right.$ at $\left.94^{\circ} \mathrm{C}\right)$, annealing $(15$ sec at $\left.60^{\circ} \mathrm{C}\right)$, and extension $\left(15 \mathrm{sec}\right.$ at $\left.72^{\circ} \mathrm{C}\right)$ using the thermal cycler 9600 (Perkin-Elmer). To correct for variations across different preparations, cDNA samples were adjusted to equal input cDNA concentrations based on their $\beta$-actin content before determination of cytokine cDNA content. Control PCRs without cDNA were performed in all experiments to exclude contamination.

Data analysis. Data were analyzed by Mann-Whitney $U$ test or Fisher's exact test, and $p<0.05$ was considered statistically significant.

\section{RESULTS \\ Susceptibility to experimental autoimmune encephalomyelitis}

APO-SUS and APO-UNSUS rats showed a clear difference in susceptibility to EAE (Fig. 1 and Table 1). APO-SUS rats were less susceptible for EAE. The incidence of disease and the mean cumulative clinical score were lower in APO-SUS animals than in APO-UNSUS animals. In addition, there was a significant difference in the kinetics of disease development. APO-SUS animals showed a significant delay with respect to onset of the disease when compared with APO-UNSUS rats. The first symptoms of disease were observed only at day 12 after inoculation in APOSUS rats. In contrast, APO-UNSUS rats showed the first symptoms of the disease at day 8 after inoculation, the degree of paralysis increased reaching maximal levels at day 11 after inoculation in these animals; subsequently, disease activity gradually decreased, and complete remission was observed after $18 \mathrm{~d}$. There was no group-specific difference in duration of the disease.

\section{Response to inoculation with Trichinella spiralis}

APO-SUS rats developed a higher level of anti-T. spiralis IgE than APO-UNSUS rats (Fig. 2). In eight of nine APO-SUS animals, $T$. spiralis-specific antibodies of the IgE subclass could be detected, 


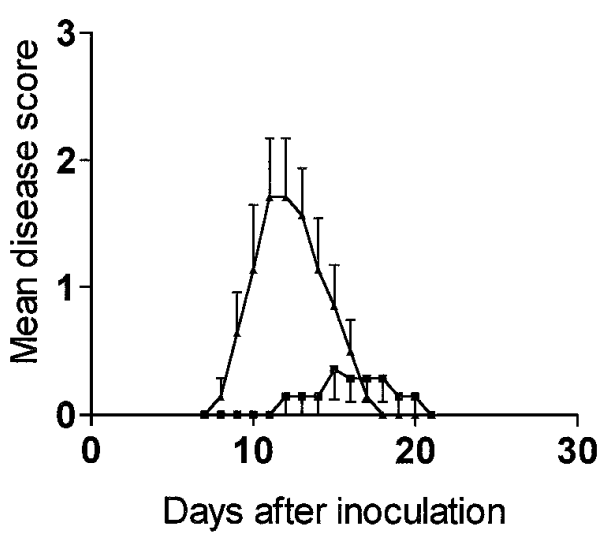

Figure 1. Expression of EAE in APO-SUS and APO-UNSUS rats. Male APO-SUS $(n=7)$ and APO-UNSUS $(n=7)$ rats were inoculated with MBP in CFA on day 0. Clinical signs of the disease were scored daily on a scale from 1 to 5 as described in Materials and Methods. For statistical analysis of the data, see Table 1 .

Table 1. Susceptibility to EAE of APO-SUS and APO-UNSUS rats

\begin{tabular}{llll} 
& APO-SUS & APO-UNSUS & $p$ \\
\hline Incidence $^{a}$ & $3 / 7$ & $7 / 7$ & $0.04^{b}$ \\
Mean day of onset $^{c}$ & $14.7(1.5)$ & $9.9(0.5)$ & $0.017^{d}$ \\
$\quad$ range & $12-17$ & $8-11$ & \\
$\quad$ median & 15 & 10 & \\
Duration $^{e}$ & $4.3(2.5)$ & $6(2.6)$ & $\mathrm{ns}^{d}$ \\
$\quad$ range & $2-7$ & $3-9$ & \\
$\quad$ median & 4 & 7 & \\
Mean cumulative score $^{f}$ & $1.9(1)$ & $9.2(2.9)$ & $0.018^{d}$ \\
$\quad$ range & $0-7$ & $3-22$ & \\
median & 0 & 7 & \\
\hline
\end{tabular}

Animals were inoculated with MBP in CFA, and the clinical expression of the disease was determined as described in the legend to Figure 1.

${ }^{a}$ Number of animals with disease/number tested; disease was defined as clinical score $\geq 1$.

${ }^{b}$ Fisher's exact test.

${ }^{c}$ Average day of disease onset of those animals that developed disease (SEM).

${ }^{d}$ Mann-Whitney two sample test.

${ }^{e}$ Average duration of the disease in days in those animals that developed disease (SEM).

${ }^{f}$ Value represents the mean of the maximum EAE score for each group.

whereas only two of seven APO-UNSUS rats developed detectable levels of parasite-specific IgE.

There were no group-specific differences in the levels of IgG or IgA specific for $T$. spiralis (Table 2).

\section{Production and/or mRNA expression of Th1 and Th2 type cytokines}

The splenocytes of APO-SUS and APO-UNSUS rats did not show group-specific differences in the capacity to produce IFN- $\gamma$ after mitogenic stimulation (Table 3). Moreover, neither the expression of IFN- $\gamma$ mRNA nor that of IL-4 mRNA differed between both lines, although the expression of IL-4 was slightly, but not significantly, greater in APO-SUS rats than in APO-UNSUS rats ( $p=0.06$; Table 4). However, the relative contribution of Th1 cells versus Th 2 cells, as expressed in terms of the ratio IFN mRNA/IL-4, was significantly greater in APO-UNSUS rats than in APO-SUS rats $(p=0.03$; Table 4).

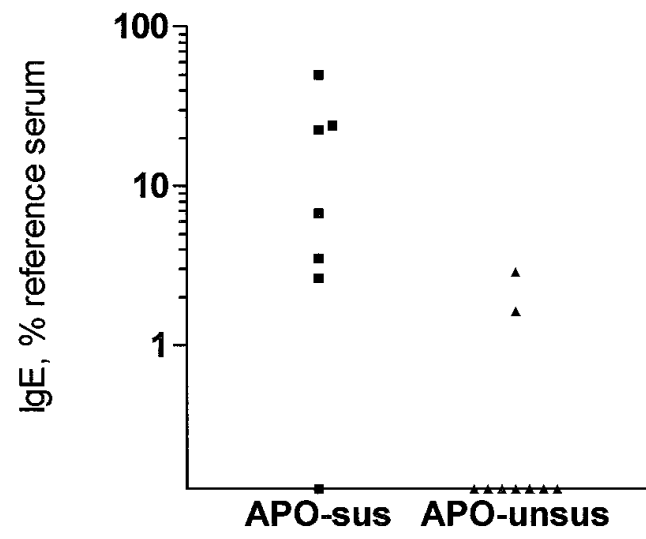

Figure 2. Specific anti-T. spiralis IgE titers in APO-SUS and APOUNSUS rats. Seven APO-SUS rats and nine APO-UNSUS rats were infected with $T$. spiralis and killed 6 weeks after infection. Serum was collected and levels of specific anti- $T$. spiralis antibodies were determined by ELISA. Specific IgE antibodies could be detected in 6 of 7 APO-SUS rats and in 2 of 9 APO-UNSUS rats (Fisher's exact test, $p=0.04$ ).

Table 2. Anti-T. spiralis antibody titers in serum

\begin{tabular}{llllll} 
& APO-SUS & & & \multicolumn{2}{c}{ APO-UNSUS } \\
\cline { 2 - 3 } \cline { 5 - 6 } & Detectable $^{a}$ & Titer $^{b}$ & & Detectable & Titer \\
\hline IgA & $4 / 7$ & $80.8 \pm 10.7$ & & $4 / 9$ & $54 \pm 25$ \\
IgG & $7 / 7$ & $10.7 \pm 3.5$ & & $9 / 9$ & $7.7 \pm 2.7$ \\
IgE & $6 / 7$ & $18.2 \pm 7.4$ & & $2 / 9^{*}$ & $7.3 \pm 5.7$ \\
\hline
\end{tabular}

Rats were infected with $T$. spiralis and killed 6 weeks after infection. Serum was collected, and levels of specific anti-T. spiralis antibodies were determined by ELISA. ${ }^{a}$ Number of animals with detectable level of antibodies/number of animals tested.

${ }^{b}$ Mean concentration of antibody \pm SEM in those animals with detectable antibodies expressed as percentage of a reference serum.

*Fisher's exact test: $p=0.04$.

Table 3. Production of IFN- $\gamma(\mathrm{ng} / \mathrm{ml})$ by splenocytes from APO-SUS and APO-UNSUS rats

\begin{tabular}{lll} 
& $\begin{array}{l}\text { APO-SUS } \\
(n=6)\end{array}$ & $\begin{array}{l}\text { APO-UNSUS } \\
(n=6)\end{array}$ \\
\hline Mean (SEM) & $10.2(2.2)$ & $6.6(0.6)$ \\
Range & $4.5-19.7$ & $5.1-9.3$ \\
Median & 9.6 & 6.2
\end{tabular}

Splenocytes from naive APO-SUS and APO-UNSUS rats were cultured for $20 \mathrm{hr}$ in the presence of PMA and ionomycine. The level of IFN- $\gamma$ in the culture supernatant was determined by ELISA.

Mann-Whitney two sample test: $p=0.31$.

\section{DISCUSSION}

The present study confirms and expands our previous findings that the susceptibility to EAE was significantly smaller in APO-SUS rats than in APO-UNSUS rats; when compared with APOUNSUS rats, the severity of clinical symptoms of EAE was significantly less and the onset was significantly delayed (see Fig. 1 and Table 1 in Cools et al., 1993). In contrast, APO-SUS rats have a significantly larger response to infection with the nematode $T$. spiralis than APO-UNSUS rats: the level of parasite-specific IgE was significantly higher in APO-SUS rats than in APO-UNSUS rats, although the levels of parasite-specific levels of $\operatorname{IgA}$ and $\mathrm{IgG}$ did not differ between both lines in this model for Th2-dependent infectious diseases (Table 2, Fig. 2). In line with these data, the 
Table 4. Expression of mRNA for IL-4 and IFN- $\gamma$ after polyclonal activation of splenocytes from APO-SUS and APO-UNSUS rats

\begin{tabular}{llll} 
& $\begin{array}{l}\text { APO-SUS } \\
(n=6)\end{array}$ & $\begin{array}{l}\text { APO-UNSUS } \\
(n=6)\end{array}$ & $p^{a}$ \\
\hline $\mathrm{IL}^{b}{ }^{b}$ & $0.5(0.14)^{c}$ & $0.14(0.04)$ & 0.06 \\
$\mathrm{IFN}^{c} \gamma$ & $1.7(0.2)$ & $1.17(0.17)$ & $\mathrm{NS}^{d}$ \\
Ratio IFN- $\gamma$ :IL-4 & $3.5(0.5)$ & $6.4(0.75)$ & 0.03
\end{tabular}

Splenocytes from naive APO-SUS and APO-UNSUS rats were cultured for $20 \mathrm{hr}$ in the presence of PMA and ionomycine. Cells were harvested and RNA was extracted. The level of expression of mRNA for IL- 4 and IFN- $\gamma$ was determined by quantitative competition RT-PCR.

${ }^{a}$ Mann-Whitney two sample test.

${ }^{b}$ The level of IL-4 and IFN- $\gamma$ cDNA is expressed in units as defined in Materials and Methods.

${ }^{c}$ Data represent mean and (SEM).

${ }^{d} \mathrm{NS}$, not significant.

present study shows that the relative contribution of Th1 and Th2 type responses significantly differed between both lines; as shown in Table 4, the ratio of the mRNA expression for the Th1 cytokine IFN- $\gamma$ and for the Th2 cytokine IL- 4 in splenocytes was much smaller in APO-SUS rats than in APO-UNSUS rats. These data together show that APO-SUS and APO-UNSUS rats show groupspecific differences in their susceptibility to inflammatory and infectious diseases, respectively.

Given the features of APO-SUS and APO-UNSUS rats mentioned in the introductory remarks, it can be concluded that the structure and reactivity of the neuroendocrine system of APOSUS and APO-UNSUS rats is consistently coupled to a groupspecific reactivity of the immune system in two fundamentally different disease models, namely the EAE model for a Th1dependent autoimmune disease and the immune response to infection with the nematode $T$. spiralis for a Th2-dependent infectious disease.

The question arises whether the group-specific differences in the structure and reactivity of the HPA axis actually direct the group-specific differences in the balance between the responses of Th1 and Th2 cells. As mentioned in the introductory remarks, APO-SUS rats have higher plasma levels of ACTH at rest and in response to a stressor (Rots et al., 1996b). Moreover, stressinduced increases in corticosteroids are higher and last longer in APO-SUS animals (Rots et al., 1996b). Glucocorticoids are known to be capable of favouring a Th2 type of response. In vitro administration of glucocorticoids to cultures of murine $\mathrm{T}$ cells selectively inhibits the response of Th1 cells (Daynes and Araneo, 1989; Daynes et al., 1990). In addition, in the presence of glucocorticoids, the differentiation and/or activation of Th2 cells is favored (Daynes and Araneo, 1989; Daynes et al., 1990). Furthermore, stress-induced increases in glucocorticoids can stimulate production of the Th2 cytokine IL-4 (Moynihan et al., 1994). Glucocorticoids not only favor the production of Th2 cytokines over Th1 cytokines but are also capable of enhancing the secretion of IgE by B cells in the presence of IL-4 (Nusslein et al., 1994). These data, together with the group-specific differences in susceptibility to Th1- and Th2-dependent immune diseases, give rise to the hypothesis that the group-specific differences in the structure and, especially, reactivity of the HPA axis direct the balance between the responses of Th1 and Th2 cells in APO-SUS and APO-UNSUS rats.

The role of HPA axis reactivity in the inflammatory process in the disease EAE has been suggested in other animal models as well. In the inbred strain of Lewis rats, which are highly suscep- tible to EAE, it has been shown that the responsiveness of the HPA axis is impaired (Sternberg et al., 1989a,b). The impaired functioning of the HPA axis in Lewis rats has been ascribed to a defect in the hypothalamic secretion of CRH (Sternberg et al., 1989b). In this respect it is of interest that APO-UNSUS animals express lower levels of CRH mRNA in the paraventricular nucleus of the hypothalamus than APO-SUS animals (Rots et al., 1995). Administration of glucocorticoids to inflammatory autoimmune disease-sensitive Lewis rats renders them into resistant animals (Sternberg et al., 1989a,b). On the other hand, resistant Fischer F344 rats can be rendered into highly susceptible animals by administration of the glucocorticoid receptor antagonist RU 486 (Sternberg et al., 1989a,b). In the mouse model, two inbred strains have been described that differ in the dominance of responses of Th1 or Th2 cells as well as in the reactivity of the neuroendocrine system. BALB/c mice respond predominantly with a Th2 type response, whereas C57/b16 mice respond with a Th1 type response (Scott et al., 1989; Heinzel et al., 1991). It is of interest that these two strains display differences in the reactivity of the HPA axis that are similar to the differences between APO-SUS and APO-UNSUS rats: stress-induced increases in $\mathrm{BALB} / \mathrm{c}$ mice are larger than in C57/bl6 mice (Shanks et al., 1994). Together, these data support the hypothesis that the structure and, especially, the reactivity of the HPA axis direct the Th1/Th2 balance.

In comparison with the above-mentioned animal models, the model of APO-SUS and APO-UNSUS rats has several advantages, of which only two are mentioned below. First, the procedure used to breed APO-SUS and APO-UNSUS rats guarantees the maintenance of the originally present genotypic heterogeneity, apart from the alleles at the loci involved in the determination of the selected traits; this matches the human situation far better than animal models with different inbred strains of rodents because such inbred strains, unlike humans, are each marked by a genotypic uniformity. Second, the available knowledge about group-specific differences in structure of the brain and body, as well as in behavior of APO-SUS and APO-UNSUS rats, is far greater than that of the mentioned inbred strains. Such knowledge is a prerequisite for analyzing additional mechanisms and factors that modulate, control, or direct individual-specific differences in susceptibility to inflammatory and infectious diseases. In this respect, it is relevant to mention that the group-specific differences in the structure and reactivity of the brain of APO-SUS and APO-UNSUS rats are consistently and causally coupled to groupspecific differences in behavioral responses to internal and external challenges (coping styles). This makes these rats very useful models for studying the complex relation between individualspecific vulnerability for immune diseases and different coping styles.

Recently, we have found that APO-SUS and APO-UNSUS rats differ also in the adrenergic reactivity of the peripheral and CNS. Apart from the finding that the basal plasma level of adrenaline is lower in APO-SUS rats than in APO-UNSUS rats that may result in relatively hypersensitive $\beta_{2}$-adrenergic receptors, the stressinduced increase in adrenaline is much higher in APO-SUS rats than in APO-UNSUS rats (Rots, 1995). Therefore, the adrenergic system may be more effective in modulating responses in APOSUS rats than in APO-UNSUS rats. Cells of the immune system express $\beta_{2}$-adrenergic receptors and from in vitro experiments it is known that adrenaline can selectively influence the reactivity of Th1 or Th2 cells (Johnson and Gordon, 1981). The increase in intracellular cAMP after activation of $\beta_{2}$-adrenergic receptors 
results in increased IL-4 production (Paul-Eugene et al., 1993; Lacour et al., 1994; Katamura et al., 1995). Moreover, $\beta_{2}$ adrenergic agonists can stimulate IL-4-dependent IgE synthesis (Paul-Eugene et al., 1993, 1995). We have data showing that $\beta_{2}$-adrenergic agonist inhibit IFN- $\gamma$ production, resulting in a shift toward Th2 type responses (A. Kavelaars, unpublished data). Thus, the relatively increased responsiveness of $\beta_{2}$-adrenergic receptors in APO-SUS rats may also contribute to the relatively increased ratio of IL-4 over IFN- $\gamma$ production. Therefore, the difference in Th1/Th2 balance between APO-SUS and APOUNSUS animals could also be partly a result of the difference in the reactivity of the adrenergic system.

In conclusion, our data from the in vivo experiments are consistent with the hypothesis that the high reactivity of the HPA axis in APO-SUS animals can facilitate differentiation to Th2 type effector cell response and enhance IgE secretion, resulting in high IgE titers after infection with $T$. spiralis. Conversely, the low reactivity of the HPA axis in APO-UNSUS rats results in susceptibility to inflammatory autoimmune disease that is mediated via Th1 type $\mathrm{T}$ cells.

\section{REFERENCES}

Cools AR, Brachten R, Heeren D, Willemen A, Ellenbroek B (1990) Search after neurobiological profile of individual-specific features of Wistar rats. Brain Res Bull 24:49-69.

Cools AR, Rots NY, Ellenbroek B, De Kloet ER (1993) Bimodal shape of indiivdual variation in behaviour of Wistar rats: the overall outcome of a fundamentally different make-up and reactivity of hte brain, the endocrinilogical and the immunological system. Neuropsychobiology 28:100-105.

Daynes RA, Araneo BA, Dowell TA, Huang K, Dudley D (1990) Regulation of murine lymphokine production in vivo. III. The lymphoid tissue microenvironment exerts regulatory influences over $\mathrm{T}$ helper cell function. J Exp Med 171:979-996.

Daynes RA, Araneo BA (1989) Contrasting effects of glucocorticoids on the capacity of $\mathrm{T}$ cells to produce the growth factors interleukin-2 and interleukin-4. Eur J Immunol 19:2319-2325.

Finkelman FD, Pearce EJ, Urban Jr JF, Sher A (1991) Regulation and biological function of helminth-induced cytokine responses. Immunol Today 12:62-66.

Heijnen JJ, Kavelaars A, Ballieux RE (1990) Corticotropin releasing hormone and pro-opiomelanocortin-derived peptides in the modulation of immune function. In: Psychoneuroimmunology II (Ader R, Felten DL, Cohen N, eds), pp 429-446. San Diego: Academic.

Heinzel FP, Sadick MD, Mutha SS, Locksley RM (1991) Production of IFN- $\gamma$, IL-2, IL-4, and IL-10 by $\mathrm{CD}^{+}$lymphocytes in vivo during healing in progresive murine leishmaniasis. Proc Natl Acad Sci USA 88:7011-7015.

Johnson DL, Gordon MA (1981) Characteristics of adrenergic binding sites associated with murine lymphocytes isolated from spleen. J Immunopharmacol 3:205-219.

Katamura K, Shintaku N, Yamauchi Y, Fukui T, Ohshima Y, Mayumi M, Furusho K (1995) Prostaglandin E2 at priming of naive CD4 ${ }^{+} \mathrm{T}$ cells inhibits acquisition of ability to produce IFN- $\gamma$ and IL-2, but not IL-4 and IL-5. J Immunol 155:4604-4612.

Lacour M, Arrighi JF, Muller KM, Carlberg C, Saurat JH, Hauser C (1994) cAMP upregulates IL-4 and IL-5 produciton from activated $\mathrm{CD}^{+} \mathrm{T}$ cells while decreasing IL-2 release and NF-AT induction. Int Immunol 6:1333-1343.

Liblau RS, Singer SM, McDevitt HO (1995) Th1 and Th2 CD4 ${ }^{+}$T cells in the pathogenesis of organ specific autoimmune diseases. Immunol Today 16:34-38.

Macphee IAM, Antoni FA, Mason DW (1989) Spontaneous recovery of rats from experimental allergic encephalomyelitis is dependent on regulation of the immune system by endogenous adrenal corticosteroids. $\mathrm{J}$ Exp Med 169:431-445.

Madden KS, Sanders VM, Felten DL (1995) Catecholamine influences and sympathetic neural modulation of immune responsiveness. Annu Rev Pharmacol Toxicol 35:417-448.
Mosmann TR, Sad S (1996) The expanding universe of T cell subset: Th1, Th2 and more. Immunol Today 17:138-146.

Moynihan JA, Karp JD, Cohen N, Cocke R (1994) Alterations in interleukin- 4 and antibody production following pheromone exposure: role of glucocorticoids. J Neuroimmunol 54:51-58.

Munck A, Guyre PM (1990) Glucocorticoids and immune function. In: Psychoneuroimmunology, 2nd Ed (Ader R, Felten DL, Cohen N, eds), pp 447-474. San Diego: Academic.

Nusslein HG, Weber G, Kalden JR (1994) Synthetic glucocrticoids potentiate IgE synthesis: influence of steroid and nonsteroid hormones on human in vitro IgE secretion. Allergy 49:365-370.

Paul-Eugene N, Kolb JP, Calenda A, Gordon J, Kikutani H, Kishimoto T, Mencia-Huerta JM, Braquet P, Dugas B (1993) Functional interaction between $\beta 2$-adreneroceptor agonists and interleukin- 4 in the regulation of $\mathrm{CD} 23$ expression and release and $\mathrm{IgE}$ production in human. Mol Immunol 30:157-164.

Paul-Eugene N, Pene J, Bousquet J, Dugas B (1995) Role of cyclic nucleotides and nitric oxide in blood mononuclear cell IgE production stimulated by IgE. Cytokine 7:64-69.

Piazza PV, Deminiere J, Le Moal M, Simon H (1989) Factors that predict individual vulnerablility to amphetamine self-administration. Science 245:1511-1513.

Piazza PV, Deminiere JM, Le Moal M, Simon H (1990a) Stress- and pharmacologically-induced behavioural sensitization increases vulnerability to acquisition of amphetamine self-administration. Brain Res 514:22-26.

Piazza PV, Deminiere JM, Maccari S, Mormede P, Le Moal M, Simon H (1990b) Individual reactivity to novelty predicts probability of amphetamine self-administration. Behav Pharmacol 1:339-345.

Rook GAW, Hernandez-Pando R, Lightman SL (1994) Hormones, peripherally activated prohormones and regulation of the Th1/Th2 balance. Immunol Today 15:301-303.

Rots NY (1995) Dopamine and stress, studies with genetically selected rat lines. PhD thesis, University of Leiden.

Rots NY, Cools AR, de Jong J, De Kloet ER (1995) Corticosteroid feedback resistance in rats geneticaly selected for increased dopamine responsiveness. J Neuroendocrinol 7:153-161.

Rots NY, Cools AR, Berod A, Voorn P, Rostene W, De Kloet ER (1996a) Rats bred for enhanced apomorphine susceptibility have elevated tyrosine hydroxylase mRNA and dopamine D2-receptor binding sites in nigrostriatal and tuberofundibular dopamine systems. Brain Res 710:189-196.

Rots NY, Cools AR, Oitzl MS, de Jong J, Sutanto W, De Kloet ER (1996b) Divergent prolactin and pituitary-adrenal activity in rats selectively bred for different dopamine responsiveness. Endocrinology 137:1678-1686.

Schlumpf M, Lichtensteiger W, van Loveren H (1994) Impaired host resistance to Trichinella spiralis as a consequence of prenatal treatment of rats with diazepam. Toxicology 94:223-230.

Scott P, Pearce E, Cheever AW, Coffman RL, Sher A (1989) Role of cytokines $\mathrm{CD} 4^{+} \mathrm{T}$-cell subsets in the regulation of parasitic immunity and disease. Immunol Rev 112:161-182.

Shanks N, Griffiths J, Anisman H (1994) Central catechlamine alterations induced by stressor exposure: analysis in recombinant inbred strains of mice. Behav Brain Res 63:25-33.

Siegling A, Lehnman M, Platzer C, Emmrich F, Volk HD (1994) A novel multispecific competitor fragment for quantitative PCR analysis of cytokine gene expression in rats. J Immunol Methods 177:23-28.

Sternberg EM, Hill JM, Chrousos GP, Kamilaris T, Listwak SJ, Gold PW, Wilder RL (1989a) Inflammatory mediator-induced hypothalamic-pituitary-adrenal axis activaion is defective in streptococcal cell wall arthrits-susceptible Lewis rat. Proc Natl Acad Sci USA 86:2374-2378.

Sternberg EM, Young WS, Bernardini R, Calogero AE, Chrousos GP, Gold PW, Wilder RL (1989b) A central nervous system defect in biosynthesis of corticotropin releasing hormone is associated with susceptibility to streptococcal cell wall-induced arthritis in Lewis rats. Proc Natl Acad Sci USA 86:4771-4775.

Van der Meide PH, Borman TH, De Labie MCDC, Wubben JAM, Botman CAD, Vijverberg K, Schellekens H (1990) A sensitive two-site enzyme immunoassay for the detection of rat interferon- $\gamma$ in biological fluids. J Interferon Res 10:183-189. 